\title{
GCU
}

Glasgow Caledonian

University

University for the Common Good

\section{The tipping point: fateful moments in child protection}

Kettle, Martin

Published in:

Child and Family Social Work

DOI:

$10.1111 /$ cfs. 12253

Publication date:

2017

Document Version

Author accepted manuscript

Link to publication in ResearchOnline

Citation for published version (Harvard):

Kettle, M 2017, 'The tipping point: fateful moments in child protection', Child and Family Social Work, vol. 22 , no. S4, pp. 31-39. https://doi.org/10.1111/cfs.12253

\section{General rights}

Copyright and moral rights for the publications made accessible in the public portal are retained by the authors and/or other copyright owners and it is a condition of accessing publications that users recognise and abide by the legal requirements associated with these rights.

Take down policy

If you believe that this document breaches copyright please view our takedown policy at https://edshare.gcu.ac.uk/id/eprint/5179 for details of how to contact us. 


\section{Abstract}

Social workers working to protect children face the prospect of making very finely balanced judgments, often on the basis of incomplete information. Based on doctoral research into sensemaking by social workers, this paper explores aspects of the tipping point, that is where the categorization of a child's situation changes, potentially leading to a very different response to their needs. Those aspects include identifying the triggers for, and consequences of, the tipping point, and being aware that the tipping point being reached may be to do with changes in the internal world of the worker as well as changes in the circumstances of the family.

This paper stresses the need for a more nuanced understanding of the tipping point, and emphasizes the need to take account of the processes of decision making, and of looking at both inter- and intra- personal components of those processes. Further, it is argued that a cautious attitude requires to be taken towards technical- rational solutions and that there is a real need to place professional judgment and consideration of the tacit dimension at the heart of the child protection process.

Keywords: Child Protection, Risk in Social Work, Child Welfare, Empirical Research

\section{Introduction}

In November 2013, the Serious Case Review (SCR) into the death of Daniel Pelka was published (Coventry LCSB, 2013). Daniel's mother and her partner were convicted of his murder. The SCR and subsequent "Deeper Analysis" (Coventry LCSB, 2014) concluded that the application of thresholds were too high and opportunities to protect Daniel were missed. This SCR is not unusual in its lack of exploration of the sense-making (Weick, 1995) of the professionals, in particular social workers, involved (Ferguson, 2009; Preston-Shoot, 2010; Stanford, 2010).

"If we are to have a debate about what might be done, it must start with some clarity about how social workers in their day to day work 'think'" (White, 2011, p. 183).

This paper offers a contribution towards achieving that clarity. Based on one aspect of my doctoral research, a constructivist grounded theory (Charmaz, 2006, 2013) study of child protection social work (Author, 2013), this paper explores the notion of the "tipping point" and argues that there is a need for much more detailed exploration from the perspective of 
the social worker of the processes by which threshold judgments are arrived at. Although written in a Scottish context, it is contended that there are implications for the rest of the UK, and possibly beyond.

\section{Scottish context}

It is first of all necessary to place this study in its context, which has three main aspects, namely child protection reform, the reform of social work and Getting it Right for Every Child (GIRFEC).

It has been argued that reviews into the deaths of children, Serious (or in Scotland, Significant) Case Reviews (SCRs) have had a disproportionate, impact on policy (Hill, 1990; Manthorpe and Stanley, 2004; Parton, 2004). Two SCRs have been of particular influence in Scotland in recent times. The Kennedy McFarlane SCR (Hammond, 2001) led to a national audit, the title of which "It's Everyone's Job to Make Sure I'm Alright" (Scottish Executive, 2002) was chosen to stress the broader corporate responsibility for child protection. Whilst there was a clear emphasis on corporate responsibility, social workers and their decisions were seen as central. "Outcomes for children were found to be highly dependent on social work doing well" (Scottish Executive, 2002, p. 11). In May 2003 the review into the death of Caleb Ness was published, (O'Brien et al., 2003) which found a series of systemic failures and led to the introduction of a programme of multi-agency inspections of services to protect children (HMle, 2010; Care Inspectorate 2013). A further policy strand was the issuing of guidance of which there has been a plethora (Scottish Government, 2010c, 2012a, 2014), including the National Risk Assessment Framework (Scottish Government, 2012b) which offered a range of tools to be used in the assessment and management of risk.

However, as well as child protection in general, social work as a profession has undergone significant scrutiny in its own right. The 21st Century Review (Changing Lives) (Scottish Executive, 2006 a, b) concluded inter alia that a new approach to risk was required (Ritchie and Woodward, 2009).

The last strand of policy that is relevant for this paper is GIRFEC, the Scottish Government's broader change agenda for children's services, with its emphasis is on early and effective intervention with children and their families. The cautious view is that progress has been made 
(Scottish Government, 2010b). However tensions remain between an emphasis on meeting the needs of all children and a focus on meeting the needs of the most vulnerable (Aldgate and Rose, 2009; Buchanan, 2009).

Placing this discussion in a broader, although still Scottish, context a report of inspection into child protection in Scotland published in 2013 found much to be optimistic about. For those children who were formally identified as in need of protection generally agencies were seen as working together effectively. However the, "overall picture in respect of children whose names were not on the Child Protection Register was more complex and less encouraging" (Care Inspectorate, 2013, p. 10).

Looking at this complex policy agenda through the eyes of the front line social worker, while It's Everyone's Job argues that child protection is everyone's responsibility, Changing Lives makes it very clear that risk is the responsibility of social work in particular, and GIRFEC stresses the importance of meeting need as a way of reducing risk. These inherent tensions have to be managed by front line practitioners, in particular social workers, who have to operate within a context of a discourse about risk that is fluid. Further, a recurring theme is the importance of decision points in the lives of children and their families, and the complexity of the context within which those decisions are made.

\section{Thresholds}

The issue of thresholds recurs throughout the SCR literature in particular (Vincent and Petch, 2012) and indeed one view is that there is a, "preoccupation with thresholds" (Brandon et al., 2008 b, p. 313) in cases where children die or are seriously harmed. In a detailed exploration of the issues, Brandon and colleagues start with Lord Laming's assertion in the Victoria Climbié report that 'child protection cases do not always come labelled as such' (Laming, 2003, para 17.106). That quote reinforces the point that a case becoming child protection is a complex process of categorization and response, and there sometimes requires to be something of a struggle for a child's circumstances to be treated as child protection. In particular, responding to the issue of neglect raises real challenges around thresholds (Buckley, 2003; Scourfield and Pithouse, 2006). Further, Horwath (2007) stresses what she calls "the missing assessment domain" of personal, professional and organisational factors in reaching decisions about 
neglect. Further, thresholds are seen as having a significant organisational component. (Davies and Ward, 2012).

As Platt and Turney (2012) argue, an overly simplistic representation of thresholds demonstrates a failure to understand the experience of that particular child. Further, a rationality is assumed that does not exist in practice and in so doing fails to address the complexity of the process. Building on the work of Klein $(2008,2011)$ they argue that attempts to define thresholds more accurately are unlikely to be successful and instead more likely to divert attention away from what is a much more important activity, that is understanding the thinking processes of those involved in making what they refer to as 'threshold decisions' in practice. Having established the context, and explored the issue of thresholds, this paper will now turn to the research that underpins it.

\section{Methodology}

The doctoral study that this paper draws was a grounded theory study of child protection social work and involved 22 in-depth interviews with social workers working in child protection in one local authority in Scotland, and detailed analysis of 20 SCRs. It is important to acknowledge that there are a number of variants of grounded theory that have been developed from the seminal text (Glaser and Strauss, 1967) and differences between them are a matter of considerable debate (see, for example, Wasserman et al., 2009; Birks and Mills, 2011; Urquhart, 2013). Constructivist grounded theory was chosen because of its emphasis on research participants as co-constructors of the data and its underpinning epistemological assumptions that knowledge is constructed, not waiting to be discovered (Charmaz, 2006, 2013). This methodological approach was selected with the aim of generating a theory of social workers' perspectives on child protection work and because it aimed to generate theory, particularly in the mid-range (Oktay, 2012).

Grounded theory is a methodology characterized by its iterative nature. In particular, the constant comparison method is one of the key ways in which grounded theory is differentiated from other qualitative approaches (Flick, 2009). Indeed the title of Hallberg's (2006) paper contends that the constant comparison method is the "core category" for grounded theory. This involves abductive reasoning, that is starting with the data, working through a process of open and focused coding and subsequently moving back and forwards between inductive and deductive reasoning but ultimately towards hypothesis formation (Charmaz, 2006, 2013; 
Reichertz, 2007). Closely connected to the idea of constant comparison is theoretical sampling, the main principle of which is that the emerging categories and the researcher's increasing understanding of the developing theory direct the sampling (Morse, 2007)). Charmaz (2006, p.100) puts it bluntly, "Initial sampling in grounded theory is where you start, theoretical sampling tells you where to go". The last key aspect of grounded theory is the writing of memos. It is described as "a private conversation between the researcher and his/ her data" (Lempert, 2007, p.251). Birks and Mills (2011) describe it as a type of research log, diary or journal. For Charmaz, $(2006$, p.72) it is "the pivotal intermediate step between data collection and writing drafts of papers.....Memos catch your thoughts, capture the comparisons that you make and crystallize questions and directions for you to take". The iterative use of the key steps of constant comparison method, theoretical sampling and memos incrementally led to the development of the theory that is presented here.

In short, grounded theory aims to answer the question, "what is going on here?" and involves building theory from the ground up. To offer one example, a number of references in early interviews to cases "going child protection" led to this being explored in more detail in later interviews and ultimately to the emergence of "the tipping point" as a core category.

\section{Findings}

This paper will now turn to an exploration of one aspect of the findings, namely the tipping point, the point at which the balance shifts and the response to, or categorization of, a case changed. Tipping points included decisions about whether children should continue to live with their parents or legal processes should be instigated to remove children from their home. The course of children's lives may be changed as a consequence, definitely in the short term, but also possibly in the much longer term. There can be a number of conditions or triggers for tipping points, which may be reached as a consequence of changes in the way the case is being responded to, or as a result of strategies being employed by both social workers and families.

The tipping point was typified by the phrase used by a significant number of participants, "going child protection", by which they meant child protection procedures being instigated.

"I think that that was the thing, there wasn't one thing... there was a real build up of extensive supports going into a house...... d do suppose that it was just at the point where I did the visit on the Friday, thought about it all weekend, went in on the Monday......and I was asking how do we move this on, and it 
was then decided that it needed to go, it needed to go child protection" (Interview 11).

This extract illustrates this process of "going child protection", with both external and internal factors. Importantly the tipping point was reached as an internal process for the worker, that she found difficult to dissemble, "That was the thing, there wasn't one thing".

There can be a number of conditions or triggers for tipping points. A key feature was often a background of a growing accumulation of concerns, making judgments more complex. Rarely did social workers have concerns about responding to individual incidents of concern, which they perceived to be bounded and as a consequence relatively easy to make sense of. Indeed, participants were, perhaps paradoxically, more comfortable with using the most draconian powers of seeking the compulsory removal of a child from their carers via a Child Protection Order (CPO) from a Sheriff because they saw these instances as most clear cut, as with this participant.

"And I do appreciate that I have not had to take a CPO yet where I have had to wriggle or struggle to explain it, and I don't know maybe that's by chance, maybe that's not by chance maybe I have just managed to avoid it, and no I think that I am very clear about when a CPO needs to be taken and when not" (Interview 13).

This paper will now turn to a consideration of the triggers for tipping points.

\section{Triggers- external}

\section{Agency triggers}

Some riggers for tipping points came from other agencies through concerns that they had identified. Sometimes this was directly, as in this example.

"The older girl had said to the teacher that she was worried that her mum was using drugs, and that she was worried about going home and so that was obviously a child protection referral as far as I could see at that point" (Interview 17).

Those external triggers were sometimes loaded with anxiety, as in the case of the social worker describing being told by a head teacher that, "this is the kind of case that ends up in the papers" (Interview 6).

However, sometimes this was indirect, for example neighbours phoning the Police following a disturbance and the Police using their emergency powers. 
"The parents were out of the game altogether, completely under the influence and the Police removed the child, and brought the child to social work" (Interview 16).

This example was of particular significance because prior to this incident the level of concern experienced by the social worker had already led to a referral to the Reporter to the Children's Hearing, who is the decision maker for the Children's Hearing system, but they had declined to take action because for them the test for compulsion had not been met, and this illustrates the complexity of negotiating tipping points as well as carrying anxiety, both their own and that of other agencies. Again, perhaps paradoxically, the reaching of the tipping point sometimes came as a relief, because it allowed for the dissipation of the anxiety, "We were worried about was going on under the surface, but you only ever see the tip of it, until something actually happens" (Interview 16).

\section{Family triggers}

External triggers could also come from extended family members, for example the grandmother who had phoned to express concerns about her daughter's mental health (Interview 9) and this underscored social workers often feeling that they were the repository of the concerns of others, reinforcing the above issue of workers feeling of the anxiety of others being passed on to them. Sometimes the triggers came from planned, or indeed unplanned contact, with families as in the example of participants who had changed their minds as a consequence of direct involvement with children or young people, for example the worker who altered his view that a child should be accommodated as a consequence of direct work undertaken with them.

\section{A fresh pair of eyes}

A key external trigger was a fresh pair of eyes, which could be deliberate, for example deliberately recruiting another member of staff to take a fresh look at a case that was viewed as being intractable. However, it could be unplanned, for example a new worker becoming involved. In this instance where a family had moved from another area it was the fresh pair of eyes that was the trigger, rather than anything that had changed in the family setting.

"In this instance there was not actually a tipping point in terms of what the parents actually did, they were just doing what they had already been doing, but what had changed was that we saw it as different here, and we had a different threshold" (Interview 14).

This was a particular issue in working with families where neglect, particularly related to parental substance misuse, was a significant issue, and where any progress was interspersed 
with periods of lapse, and there was an understanding that is a pattern to be anticipated and worked with. However there is an important caveat, the "start again syndrome" which first appeared in an overview report of Significant Case Reviews (Brandon et al., 2008a), but which specifically entered the language of participants as in this illustration.

"But I think as well there is that 'start again syndrome', from now on and we had said to them we will be taking into account that historical information" (Interview 19).

\section{Internal mechanisms}

Internal tipping points were those reached through the interior processes of the worker, some of which were intuitive and less deliberate, whilst some were conscious and deliberate. There was certainly a temporal dimension, with some tipping points having been reached very quickly, and some over a longer timescale.

\section{Immediate response}

Sometimes tipping points were reached very quickly, as with this worker who was taking a new referral and both talking to a hospital midwife and reading information on the computer at the same time.

"By the end of the conversation I think that I was quite clear that this is a pre-birth child protection and this is going to a case conference and again but you don't want to pre-empt stuff as well, because you don't want people to think that you are judging and making conclusions but the information tells me that this is the way that this is going to go" (Interview 13).

For her, the tipping point had been reached before the phone call had been ended, and this was representative of an almost intuitive response that she found difficult to clearly analyze. In other instances, the tipping point was reached intuitively, as in the data extract that opens this section, and where the worker found it difficult to dissemble the elements of the case that led her to the decision to initiate child protection procedures.

\section{Reading of patterns}

Developing the above issue of the "start again syndrome", workers sought to avoid this by, for example, the following reference to an "informed fresh pair of eyes", that is a fresh look that is informed by a detailed knowledge of what has gone on previously. 
"And I think again from the experience of that case going back to a chronology, you can bring a fresh pair of eyes to a case, but it needs to be an informed fresh pair of eyes" (Interview 21).

The construction of chronologies was a significant feature for this group of social workers. One example was participant 17 who described this in some detail, and for whom the chronology had two purposes, firstly to assist her analysis of the case, but also to challenge the analysis of another worker from another discipline, who was seen as having a very superficial understanding of the case.

When tipping points were seen as approaching, particularly in relation to young children potentially being accommodated, one of the consequences for participants was considerable anxiety and doubt. A strategy adopted was to increase the level of scrutiny in terms of seeking more evidence, or to attempt to further engage additional services, and there were occasions where saturation had been reached.

\footnotetext{
"It was also that we have nothing else to put in here we have....We have scaffolded this family, we have put everything in, and nothing has changed the circumstances, nothing has changed the situation, so there is nothing else that we could access to put in, and I felt that the kids are at daily risk, so I think that at that point that it went child protection..." (Interview 11, emphasis by participant).
}

Formal decision making fora, for example child protection case conferences, were sometimes seen as helpful in gathering the information and the professionals involved with the family together in the same room at the same time, but this was not always the case, as in the example of the participant who felt that they was the only advocate for a very small baby, whilst the other professionals were seen as having a primary concern with the parents, who both had learning disabilities. "It was my job to remind them of the wee baby at the middle of all of this" (Interview 19).

\section{Incremental tipping points}

As well as the immediate, whether planned or intuitive, there were tipping points that was reached gradually and incrementally, and where it was often not possible to unpack the reasons behind the decisions having been reached. For participants this stemmed from processing information, sometimes using supervision, sometimes reflection. However the 
common element was a gradual realization that things could not continue as they were, as this next extract indicates.

"So what that finally tipped it for you after all of that time?"

"What I now don't know is why it didn't tell us after two years that nothing was working (pause) I suppose it is only when you look back, and perhaps that explains the silence (long pause) I think that I ran out of hope for them" (Interview 15).

\section{Consequences}

When it came to tipping points being reached, it was recognized that there were consequences, some intended, some unintended, and the possible consequences could not be extricated from the decision making process itself. For example the structure of child protection processes were welcomed in that it makes organizational expectations much clearer.

"But also a recognition that this is not OK, but it is not just me that is thinking this, and other people also think that this is not good enough, and the family are pulled on board, and they have to attend the meetings, perhaps we are much more clear cut about what our expectations of the family are, and what will happen if this is not achieved" (Interview 21).

As well as "pulling families on board", there is also a sense that other agencies recognise the priority that has been afforded to child protection,

"I am someone who very much likes structure, and one of the good things because you get that child protection plan, then you have a shared responsibility, you have a shared accountability amongst the multi- agency group" (Interview 22).

However, the consequences were not always benign, and the control for professionals was sometimes seen as a loss of control for families, where they could sometimes be disempowered, where the process was "taken out of their hands".

"But the bottom line is that they have said something or something has then tipped it in that direction that other people have decided that they are at risk, and I think that it can then get to a point where....it then takes it completely out of their hands," (Interview 16).

\section{Summary}

What is suggested from this analysis of one aspect of the research is that social workers' perceptions of families and the subsequent categorization or response to those families may be influenced by external factors, that is within the family itself or with new information 
received form other agencies or family members. However, importantly the tipping point may actually come about as a result of changes in the internal world of the social worker. These changes may come about as a consequence of deliberate strategies, for example analyzing the chronology or the bringing of a fresh pair of eyes to the family but also may be the result of intuitive responses, either to a particular set of circumstances that require an immediate response, or to involvement with families over a longer period of time.

\section{Discussion}

As has already been identified tipping points had external properties, namely triggers, legal or procedural tipping points and consequences, as well as internal properties, one of which may, at least in part, be what was happening in the internal world of the social worker. It is suggested that part of the reason why the tipping point is so problematic is found in Giddens' (1991) discussion of "fateful moments" and although he is not discussing child protection directly, his analysis of their difficulty is apposite here.

"Fateful decisions are usually almost by definition difficult to take because of the mixture of the problematic and the consequential that characterises them" (p. 113-4).

The problematic in the sense of the protection of children refers to decisions being, even in the most favourable of circumstances, very difficult to make because of the different aspects that require to be considered. Further, there is substantial evidence to indicate that circumstances that social workers work in are often emotionally highly charged and ridden with anxiety (Froggett, 2002; Ferguson, 2011). Indeed, for Morrison (1997, p.196) anxiety "runs like a vein throughout the child protection process". Hughes (2009), in her exploration of anxiety as an important aspect of the child protection process, sees it as an organizational as well as an individual phenomenon. She asserts that failure to contain anxiety appropriately can have a serious negative impact for workers and for families. In particular, where hostility and aggression are faced, there is a real risk that workers' ability to reflect, make judgments and act clearly may well be impaired.

"Workers can become paralysed by their own fears and anxieties, which can lead to the assessment process remaining incomplete" (extract from serious case review overview report, cited in Brandon et al., 2008a, p. 323).

This issue of anxiety relates to the second aspect of Giddens' fateful decisions, the consequential. In the context of the protection of children this refers to the difficulty of choosing between options that may all have negative consequences and where there may be potentially very significant consequences of getting it wrong, with the risks of children be exposed to serious injury or worse, or on the other hand intervention being overly draconian. 
Platt and Turney's work on thresholds, discussed earlier in this paper is important, but this study develops it in two important aspects. Firstly it was found that tipping points were less a decision and more of a process that has a number of factors to it, including the internal world of the social worker and interactions, often complex, with other professionals. Secondly, although they refer to power in their analysis this is not as developed as it might be, and it is argued that it is essential that an appreciation of power relationships is incorporated into any understanding of the child protection process (Tew, 2003). Tew's differentiation between 'power together', that is power exercised co-operatively and in partnership with families and 'power over', that is power exercised in a potentially coercive manner is a useful lens through which to explore social workers' interactions with families.

In terms of the need for a more nuanced understanding of child protection social work, the importance of a naturalistic approach is reinforced by a growing body of evidence from both inside and outside the child protection discourse that the management of risk has within it both formal, i.e. procedural, and informal aspects to it, (Horlick-Jones, 2005; Broadhurst et al., 2010). Horwath (2007) in developing aspects of what she refers to as the "missing assessment domain" stresses, following Taylor and White (2001), that assessment is both a technical-rational activity, which depends on the application of research, theories and practice experience, but it is also a practice-moral activity, in short what they refer as both 'head' and 'heart' activity.

A very similar conclusion is reached by Keddell, (2011, pp. 18-19) whose study, "showed that decisions are a negotiated process related to moral reasoning, identities, relationship and culpability as much as the neat application of knowledge about risk factors", and this is consistent with the findings of this study. Froggett (2002) illustrates this by describing a social worker only realizing that she had left a child at risk when she was in the bath and had the time and space to reflect on what had happened, and this reinforces the finding of this study that tipping points are often to do with what is going on in the internal world of the worker. In particular, responding to the issue of neglect raises real challenges around thresholds. The ethnographic literature (Buckley, 2003; Scourfield and Pithouse, 2006) is characterized by exploration of cases "bubbling" by which is meant where concerns accumulate and a judgment requires to be made about the totality of what is going on in the case, and where a clear picture of the case has not been achieved. Dickens (2007) in his study of social workers and lawyers in care proceedings in England in responding to neglect, refers to 'catapult moments' which relates 
closely to the concept in this study of triggers, and by which he means incidents that have a disproportionate impact on outcomes for children and families.

Much of this is not new. Indeed, twenty years ago, Thorpe (1994, p. 38) argued that,

"the 'work' in social work lies not so much in the activities involving the direct delivery of services, but in the 'hidden' tasks of moral reasoning, clarification, categorization and then a decision about service".

However, it is argued that this study adds to the developing literature on 'practice- near' research (Ferguson, 2011, Winter et al., 2015) that aims to achieve a deeper understanding of how social workers work to protect children and in particular a deeper understanding of social work as processual, rather than procedural activity.

\section{Conclusion- Implications for practice}

This study puts professional judgment at the heart of the enterprise of protecting children Featherstone et al., 2014) and points to an emphasis on the development of practice wisdom and what Carr (2011) refers to as virtue ethics, where he contends that,

"it is the cultivation of virtues such as courage, temperance, justice and wisdom that really lie at the heart of exemplary professional conduct" (Carr, 2011, p. 109).

Further, there is a need to accept, understand and explore what Polanyi refers to as the tacit dimension, with his emphasis on not merely looking at things, but "dwelling in them" (Polanyi, 1966, p.18), and in this sense this reinforces and develops Howe's (1996) argument for depth rather than surface explanations. The findings of the study in its totality also suggests a cautious attitude towards technical- rational solutions, such as assessment tools. Certainly they should not be viewed as a replacement for the core activity of the development of, and opportunities to reflect upon, key interpersonal skills such as relationship building (Ruch et al., 2010), effective communication (Koprowska, 2010) and in particular the importance of analysis in assessment (Helm, 2010).

This study also points towards an emphasis on the process of child protection, rather than focusing on the individual activities that make up that process. For example, in terms of the phrase that has cropped up repeatedly for participants, "going child protection" it points to a need to emphasise and explore the going as much as, if not more than, the child protection. 
Finally, the notion of the tipping point stresses the idea of moving away from the preoccupation with thresholds and playing down the emphasis on thresholds as tangible lines to be crossed. It encourages the adoption of an awareness that triggers for tipping points may arrive from a variety of sources, including other agencies, responding to specific incidents, information coming from members of the extended family, or a change in the perspective of the social worker. That change in perspective may comes from reading the case, that is analysing the information that was available in a different way, or indeed a planned or unplanned reflection upon what is happening in the family.

This study proposes a more nuanced recognition and understanding of, and a more critical approach to, legal and processual tipping points, and of more detailed consideration of how they are approached, and what the precipitating factors might be. It also encourages a deeper level of reflection upon the possible consequences of tipping points having been reached. The consequences for workers may be about increased structure, more scrutiny or raised anxiety, for other agencies in terms of bringing about a different response, or for families and children potentially in terms of a loss of control. It encourages workers to be very mindful that child protection involvement is not, and never can be, a neutral activity.

\section{References}

Aldgate, J. and Rose, W. (2009) Assessing and Managing Risk in Getting it Right For Every Child. Scottish Government, Edinburgh.

Brandon, M., Belderson, P., Warren, C., Howe, D., Gardner, R., Dodsworth, J. \& Black, J. (2008a) Analysing Child Deaths And Serious Injury Through Abuse And Neglect: What Can We Learn? A Biennial Analysis Of Serious Case Reviews 2003-2005. Department for Children, Schools and Families, London.

Brandon, M., Belderson, P., Warren, C., Gardner, R., Howe, D. \& Dodsworth, J. (2008b) The preoccupation with thresholds in cases of child death or serious injury through abuse and neglect, Child Abuse Review, 17, 313- 330.

Broadhurst, K, Hall, C., Wastell, D., White, S. \& Pithouse, A. (2010) Risk, instrumentalism and the humane project in social work: Identifying the informal logics of risk management in children's statutory services, British Journal of Social Work, 40, 1046- 1064.

Buchanan, G. (2009) Child Protection And Risk - The Relationship Between Risk Assessment and Getting it Right for Every Child (GIRFEC): Review of National Child Protection Guidance. Edinburgh, Scottish Government. 
Buckley, H. (2003) Child Protection: Beyond The Rhetoric. Jessica Kingsley, London.

Care Inspectorate (2013) Child Protection Services - Findings of Joint Inspections 200912, Care Inspectorate, Edinburgh.

Carr, D. (2011) Virtue, Character and Emotion in People Professions: Towards a Virtue Ethics of Interprofessional Conduct. In: Towards Professional Wisdom: Practical Deliberation In The People Professions, (eds. L. Bondi, D. Carr, C. Clark \& C. Clegg). Ashgate, Aldershot.

Charmaz, K. (2006) Constructing Grounded Theory: A Practical Guide Through Qualitative Analysis, Sage, London.

Charmaz, K. (2013) Constructing Grounded Theory, $2^{\text {nd }}$ edn. Sage, London.

Coventry LCSB (2013) Serious Case Review on Daniel Pelka. Coventry, LCSB, Coventry.

Coventry LCSB (2014) Daniel Pelka Review: Retrospective Deeper Analysis and

Progress Report on Implementation Of Recommendations, Coventry LCSB, Coventry.

Davies, C. \& Ward. H. (eds)(2012) Safeguarding Children Across Services: Messages From Research. Jessica Kingsley, London.

Dickens, J. (2007), Child neglect and the law: catapults, thresholds and delay, Child Abuse Review, 16, 2, 77- 92.

Featherstone, B., White, S. and Morris, K. (2014) Re-imagining Child Protection: Towards Humane Social Work With Families. Policy Press, Bristol.

Ferguson, H. (2009) Performing child protection: Home visiting, movement and struggle to reach the abused child. Child and Family Social Work, 14, 471- 480.

Ferguson, H. (2011) Child Protection Practice. Palgrave, London.

Flick, U. (2009) An Introduction to Qualitative Research, $4^{\text {th }}$ edn. Sage, London.

Froggett, L. (2002) Love, Hate and Welfare. Policy Press, Bristol.

Giddens, A. (1991) Modernity and Self-Identity: Self And Society in the Late Modern Age. Polity Press, Cambridge.

Glaser, B. \& Strauss, A. (1967) The Discovery Of Grounded Theory. Aldine, New York. 
Hallberg, L. (2006) The "core category" of grounded theory: making constant comparisons. International Journal of Qualitative Studies on Health and Well-being, 1, 141-148.

Hammond, H. (2001) Child protection inquiry into the circumstances surrounding the death of Kennedy McFarlane d.o.b. 17 April 1997.

Helm, D. (2010) Making Sense Of Child And Family Assessment. Jessica Kingsley, London.

Her Majesty's Inspectorate of Education (HMle) 2010, How Well Are Scotland's Children Protected? HMle, Edinburgh.

Hill, M. (1990) The manifest and latent lessons of child abuse inquiries, British Journal of Social Work, 20, 197-213.

Horlick- Jones, T. (2005) 'On risk work': Professional discourse, accountability and everyday action. Health, Risk and Society, 7, 293-307.

Horwath, J. (2007) The missing assessment domain: personal, professional and organizational factors influencing professional judgements when identifying and referring child neglect, British Journal of Social Work, 37, 1285- 1303.

Howe, D. (1996) Surface and depth in social work practice. In: Social Work Theory, Social Change And Social Work, (ed. N. Parton) Routledge, London.

Hughes, L. (2009) The most important professional relationship. In: Good Practice in Safeguarding Children: Working Effectively In Child Protection (eds L. Hughes \& H. Owen). Jessica Kingsley, London.

Keddell, E. (2011) Reasoning processes in child protection decision making: negotiating moral minefields and risky relationships, British Journal of Social Work, 41, 1251-1270.

Author (2013) A Balancing Act: A Grounded Theory Of Child Protection Social Work, Unpublished Professional Doctorate Thesis, Glasgow Caledonian University.

Klein, G. (2008) Naturalistic decision making, Human Factors: the Journal of the Human Factors and Ergonomics Society, 50, 456-460.

Klein, G. (2011) Streetlights and Shadows. Cambridge, MIT Press, Mass.

Koprowska, J. (2010) Communication and Interpersonal Skills In Social Work, 2nd edn. Learning Matters, Exeter.

Laming, H. (2003) The Victoria Climbié Inquiry. The Stationery Office, London. 
Lempert, L. (2007) Asking questions of the data: memo writing in the grounded theory tradition. In The Sage Handbook Of Grounded Theory, eds. A. Bryant \& K. Charmaz, Sage, London.

Manthorpe, J. and Stanley, N. (2004). The Age of The Inquiry: Learning and Blaming in Health And Social Care. Routledge, Basingstoke.

Morrison, T. (1997) Emotionally competent child protection organizations: Fallacy, fiction or necessity? In: Protecting Children: Challenges And Change, (eds J. Bates, R. Pugh \& N. Thompson). Arena, Aldershot.

Morse, J. (2007) Sampling in grounded theory, The Sage handbook of grounded theory, ed. A. Bryant and K. Charmaz, Sage, London, pp. 229- 244.

O'Brien, S., McKinnon, M. and Hammond, H. (2003) Report of the Caleb Ness inquiry. Edinburgh City Council, Edinburgh.

Oktay, J. (2012) Grounded Theory. Oxford University Press, Oxford.

Parton, N. (2004) From Maria Colwell to Victoria Climbié: reflections on public inquiries into child abuse a generation apart, Child Abuse Review, 13, 80-94.

Platt, D. \& Turney, D. (2012) Thresholds for child protective interventions: a conceptual analysis, British Journal of Social Work, 43, 1-19.

Polanyi, M. (1966) The Tacit Dimension. University of Chicago Press, Chicago.

Preston- Shoot, M. (2010) Looking after social work practice in its organisational context: neglected and disconcerting questions. In: Children's Services At The Crossroads: A Critical Evaluation Of Contemporary Policy For Practice, (eds P. Ayre \& M. Preston- Shoot), Russell House Publishing, Lyme Regis.

Reichertz, G. (2007) Abduction: the logic of discovery of grounded theory. In The Sage Handbook Of Grounded Theory, (eds A. Bryant \& K. Charmaz). Sage, London.

Ritchie, A. and Woodward, R. (2009), "Changing Lives: critical reflections on the social work change programme for Scotland”, Critical Social Policy, 29, 510- 532.

Ruch, G., Turney, D. \& Ward, A. (2010) Relationship-Based Social Work: Getting to the Heart Of Practice, Jessica Kingsley, London.

Scottish Executive (2002) It's Everyone's Job To Make Sure I'm Alright: The Audit And Review Of Child Protection in Scotland. Scottish Executive, Edinburgh.

Scottish Executive (2006a) Changing Lives: Report of The 21st Century Social Work Review, Scottish Executive, Edinburgh. 
Scottish Executive (2006b) Scottish Executive Response to the Report Of The $21^{\text {st }}$ Century Social Work Review, Scottish Executive, Edinburgh.

Scottish Government (2008) A guide to Getting It Right for Every Child. Edinburgh, Scottish Government.

Scottish Government (2010a) The Role Of The Registered Social Worker In Statutory Interventions: Guidance For Local Authorities, Edinburgh, Scottish Government.

Scottish Government (2010b) A Guide to Implementing Getting it Right for Every Child: Messages From Pathfinders and Learning Partners, Edinburgh, Scottish Government.

Scottish Government (2010c) National Guidance for Child Protection in Scotland, Scottish Government, Edinburgh.

Scottish Government. (2011) Practice Governance Framework: Responsibility and Accountability in Social Work Practice, Scottish Government, Edinburgh.

Scottish Government (2012a) National Guidance for Child Protection in Scotland, Scottish Government, Edinburgh.

Scottish Government. (2012b) National Risk Framework to Support the Assessment of Children and Young People, Scottish Government, Edinburgh.

Scottish Government (2014) National Guidance for Child Protection in Scotland, Scottish Government, Edinburgh.

Scourfield J. \& Pithouse, A. (2006) Lay and professional knowledge in social work: reflections from ethnographic research on child protection, European Journal of Social Work, 9, 323-337.

Stanford, S. (2010) 'Speaking back' to fear: responding to the moral dilemmas of risk in social work, British Journal of Social Work, 40, 1065- 1080.

Taylor, C. and White, S. (2001) Knowledge, truth and reflexivity: the problem of judgement in social work, Journal of Social Work, 1, 37-59.

Tew, J. (2003) Social theory, power and practice, Palgrave, London.

Thorpe, D. (1994) Evaluating Child Protection, Open University Press, Buckingham. 
Urquhart, C. (2013) Grounded Theory For Qualitative Research: A Practical Guide, Sage, London.

Vincent, S. \& Petch, A. (2012), Audit and Analysis Of Significant Case Reviews, Scottish Government, Edinburgh.

Wasserman, J., Clair, J., \& Wilson, K. (2009) Problematics of grounded theory: innovations for developing an increasingly rigorous qualitative method, Qualitative Research, 9, 355- 381.

Weick, K. (1995) Sensemaking in Organizations, Sage, London.

White, S. (2011) Fabled uncertainty in social work. In: Towards Professional Wisdom: Practical Deliberation In The People Professions, (eds. L. Bondi, D. Carr, C. Clark \& C. Clegg), Ashgate, Aldershot.

Winter, K., Hallett, S., Morrison, F., Cree, V., Ruch, G., Hatfield, M., \& Holland, S. (2015) Practice-near Research: Exploring Insights from Different Degrees of Closeness, BASPCAN Congress, Edinburgh. 
